\title{
INFRARED BASED MOISTURE MEASUREMENT
}

\author{
FILIC, M.
}

Abstract: An outstanding example of moisture measurements via an optoelectronic infrared (IR) reflectance system is described in this chapter. This measuring system consists of PbS photoconductive sensor, analogue preamplifier and PC acquiring subsystem. The input radiation has been assigned to a measuring sample by the mechanical chopper with adequate optical filters and by the mirror subsystems. Alternating reflectance from the samples at two, absorbing and not absorbing wavelengths in the near IR (NIR) region is measured by PbS photoconductive sensor; the periodical PbS output signal is amplified with a band pass analogue preamplifier and acquired by PC card with adequate software. The frequency analysis of both, the input and amplified output has been processed by the using of Fast Fourier transformation (FFT). The moisture contents in the several samples of wheat grain are experimentally estimated by described method and results are verified by the classical and very reliable thermo gravimetric method. The applied approach with all calculations and measurement results are presented in this chapter.

Key words: photoconductive sensor, moisture measurement, FFT, NIR, optoelectronic
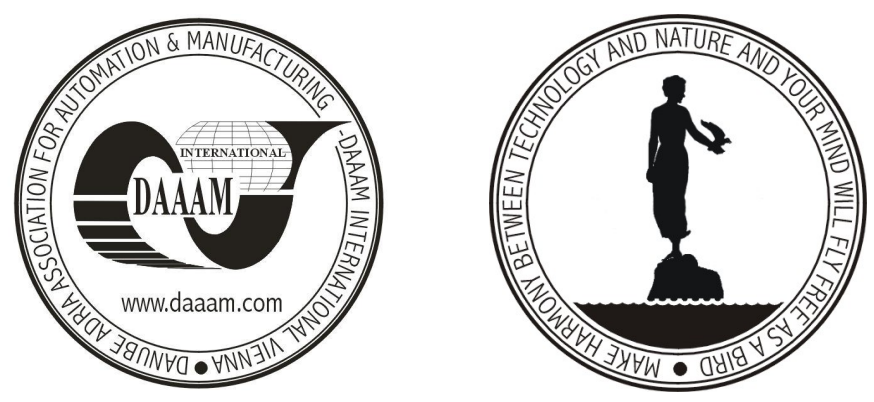

Authors' data: MSc. Filic, M[irko], Faculty of Electrical Engineering, 'J.J.Strossmayer'' Univ. of Osijek, 31000 Osijek, Croatia, Mirko.Filic@os.t-com.hr

This Publication has to be referred as: Filic, M. (2007). Infrared based moisture measurement, Chapter 32 in DAAAM International Scientific Book 2007, B. Katalinic (Ed.), Published by DAAAM International, ISBN 3-901509-60-7, ISSN 1726-9687, Vienna, Austria

DOI: $10.2507 /$ daaam.scibook.2007.32 